\title{
Long-Term Effects Secondary to Cancer Therapy in Adults
}

National Cancer Institute

\section{Source}

National Cancer Institute. Long-Term Effects Secondary to Cancer Therapy in Adults. NCI Thesaurus. Code C115227.

Side effects of cancer treatment received during adulthood occurring a long time after the treatment was completed. 